\title{
Impact of Growing Environment on Anthracnose Severity of Switchgrass Cultivars and Clones
}

Lindsey Hoffman, Department of Plant Biology and Pathology, Rutgers University, New Brunswick, NJ 08901; Laura M. Chaves, Olds College Centre for Innovation, Olds, AB T4H 1R6, Canada; Eric N. Weibel, Department of Plant Biology and Pathology, Rutgers University; Hilary S. Mayton, Center for Teaching Excellence, Garden Avenue Extension, Cornell University, Ithaca, NY 14853; and Stacy A. Bonos, Department of Plant Biology and Pathology, Rutgers University

\begin{abstract}
Hoffman, L., Chaves, L. M., Weibel, E. N., Mayton, H. S., and Bonos, S. A. 2016. Impact of growing environment on anthracnose severity of switchgrass cultivars and clones. Plant Dis. 100:2034-2042.

Anthracnose (caused by Colletotrichum navitas) has the potential to significantly reduce biomass yield of switchgrass (Panicum virgatum L.); however, limited information is available on the impact of growing environment on tolerance of switchgrass to anthracnose. Therefore, the major objectives of this study were to (i) examine genotype-environment $(\mathrm{G} \times \mathrm{E})$ effects on anthracnose severity in populations of switchgrass cultivars and individual genotypes and (ii) determine clonal repeatability estimates and stability analysis of anthracnose tolerance on individual switchgrass genotypes. Two experiments were conducted at one prime and two marginal soil locations in New Jersey. In all, 14 switchgrass cultivars were established from

seed in 2008 for experiment 1 and 50 replicated switchgrass clones were planted in 2009 for experiment 2 at all three locations. Anthracnose was rated visually in 2010 for experiment 1 and in 2010 and 2011 for experiment 2 . Significant $\mathrm{G} \times \mathrm{E}$ interactions were detected for both experiments $(P \leq$ $0.05)$ and anthracnose severity varied by location and cultivar. Clonal repeatability estimates for disease tolerance among clones was 0.78 on a clonal basis and 0.32 on a single-plant basis. Lowland ecotypes exhibited less disease overall than upland ecotypes. Results from this study indicate that selection for improved tolerance to anthracnose should be conducted after evaluation across several environments over multiple years.
\end{abstract}

In 2007, the Energy Independence and Security Act mandated that transportation fuel in the United States must include at least 36 billion gallons of renewable fuel by the year 2022 (United States Congress 2007). Furthermore, this regulation requires that a large percentage of the total be composed of advanced biofuels (such as cellulosic ethanol) instead of ethanol derived from corn (Zea mays L.). This has led to the identification and use of alternative grass species for the sustainable production of cellulosic ethanol. In particular, switchgrass (Panicum virgatum L.) has been classified as a viable alternative to corn and has earned the designation as model species for the United States Department of Energy Biofuel Feedstock Development Program.

Switchgrass is a warm-season, perennial grass that is native to most of North America (Missaoui et al. 2006). The species consists of genotypically and phenotypically different ecotypes-upland (UL) and lowland (LL) — which allows for the growth of switchgrass in diverse environmental and climatic conditions. Specifically, UL ecotypes persist in cool-humid regions, are shorter, and have many thin stems compared with LL ecotypes that persist in warmer climates and have fewer, thicker stems (Casler 2012). Along with a wide distribution range in North America, switchgrass provides many ecosystem services, including soil stabilization and erosion control, bioremediation of contaminated soils, and promotion of wildlife habitats for certain bird and animal species (Bouton 2008; Parrish and Fike 2005). One of the major advantages of using switchgrass instead of corn is the ability of the species to be produced with limited inputs (such as irrigation and fertility), and it can be grown in marginal soils not suitable for agronomic crop production (Varvel et al. 2008).

Over the past several decades, targeted breeding has resulted in significant gains in biomass yield for both UL and LL ecotypes (Casler 2012). In addition, research has classified a number of different

Corresponding author: L. Hoffman; E-mail: 1h481@scarletmail.rutgers.edu

Accepted for publication 6 May 2016.

http://dx.doi.org/10.1094/PDIS-01-16-0006-RE

(C) 2016 The American Phytopathological Society abiotic and biotic stresses that may influence stand establishment, biomass yield, and stand longevity. For example, anthracnose (caused by Colletotrichum navitas) is a pathogen that may negatively affect the cultivation of switchgrass in North America. Prior to 2009, the causal agent of switchgrass anthracnose was thought to be C. graminicola; however, Crouch et al. (2009) isolated and identified a novel Colletotrichum sp. that was appropriately named $C$. navitas ("navitas" means energy in Latin). To date, C. navitas has been detected in several states, including Pennsylvania (Sanderson 2008), New Jersey (Crouch et al. 2009), Tennessee (Li et al. 2009), and New York (Waxman and Bergstrom 2011).

Research is lacking on the direct impact that anthracnose will have on switchgrass production for ethanol. In other warm-season grass species, anthracnose has been shown to cause significant losses in biomass yield on a yearly basis. For example, anthracnose caused by $C$. sublineolum can reduce aboveground biomass of sorghum (Sorghum bicolor (L.) Moench) by approximately 20 to $40 \%$ (Pande et al. 2003), with 50\% or greater losses being detected in susceptible versus resistant lines (Thomas 1995). Similarly, farmers in India have experienced $100 \%$ loss of sugarcane (Saccharum spp.) biomass due to red rot disease caused by $C$. falcatum (Singh 2008). The main symptom of switchgrass anthracnose is foliar blight, which can ultimately result in necrosis of the entire leaf tissue (Crouch et al. 2009). This may have a direct influence on the photosynthetic capacity of the plant during the growing season and could result in decreases in both quantity and quality of harvestable biomass. Foliar diseases can also reduce the amount of cellulose available for conversion to ethanol by triggering an increase in leaf tissue lignification (Vance et al. 1980). Altogether, this information suggests that anthracnose poses a significant threat to switchgrass production for bioenergy purposes.

The potential for anthracnose to be a major limiting factor in switchgrass cultivation may be heightened by the fact that bioenergy crops are typically grown in monocultures over large acreages of land. This may increase disease pressure due to decreased genetic diversity of cultivars selected for specific traits (Gonzalez-Hernandez et al. 2009). Gravert et al. (2000) identified smut (caused by Tilletia maclagani) as the likely cause of seed and biomass yield reductions in switchgrass grown in southern Iowa as a bioenergy feedstock. 
Specifically, yield was reduced by half the expected value when smut infestation was greater than $50 \%$ in fields grown with a single cultivar of switchgrass. Therefore, in order for switchgrass to continue to be a viable option for sustainable biofuel production, research is necessary to understand the impact that anthracnose will have on production at a large-scale level and to identify methods for reducing yield losses.

One strategy for mitigating reductions in biomass due to anthracnose is to develop cultivars with increased tolerance to the disease. Research has demonstrated, however, that switchgrass cultivars vary widely in performance across different growing conditions (Casler 2010), with significant cultivar-environment interactions reported for traits such as biomass yield (Casler and Boe 2003). This indicates that breeders must screen and select germplasm for certain traits across a wide variety of environments but it is not well known whether this is the case for identifying switchgrass germplasm with improved anthracnose tolerance. In addition, research is needed to determine whether differences in anthracnose tolerance exist when comparing populations of seeded cultivars versus individual genotypes. Therefore, the major objectives of this study were to (i) examine genotype-environment effects on anthracnose severity in populations of switchgrass cultivars and individual genotypes and (ii) determine clonal repeatability estimates and perform stability analyses on tolerance of individual switchgrass genotypes grown in prime and marginal soils. To address these objectives, two separate experiments were conducted. Experiment 1 investigated the response of populations of seeded switchgrass cultivars at one prime soil location and two marginal soil locations in New Jersey. Experiment 2 determined the response of individual genotypes to anthracnose at the same locations used in experiment 1 . Clonal repeatability estimates and stability analyses were conducted using the data from experiment 2 .

\section{Materials and Methods}

Experiment 1. Plant material and soil type. Fourteen switchgrass cultivars representing both LL and UL ecotypes were evaluated in this study (Table 1). Ernst Conservation Seed (Meadville, PA) assembled all the seed lots 60 days prior to planting and stratified the seed according to Shen et al. (2001). Seed were treated with Thiram (tetramethylthiuram disulfide) and Poncho (clothianidin) (Bayer CropScience, Norcross, GA). Stratified seed from all entries were sent to the Ohio Seed Improvement Association (Dublin, $\mathrm{OH})$ for germination tests. Based on those results, seeding rates were calculated and standardized to pure live seed at approximately $11.2 \mathrm{~kg} \mathrm{ha}^{-1}$.

Table 1. Ecotype designation (upland [UL] and lowland [LL]) of 14 switchgrass cultivars evaluated at Freehold (prime land), Somerset (marginal land), and Jackson (marginal land), New Jersey

\begin{tabular}{lc}
\hline Cultivar & Ecotype designation \\
\hline Alamo & $\mathrm{LL}$ \\
Blackwell & $\mathrm{UL}$ \\
BoMaster & $\mathrm{LL}$ \\
Carthage & $\mathrm{UL}$ \\
Cave-In-Rock & $\mathrm{UL}$ \\
High Tide & $\mathrm{UL}$ \\
Kanlow & $\mathrm{LL}$ \\
KY 1625 & $\mathrm{UL}$ \\
Pathfinder & $\mathrm{UL}$ \\
Performer & $\mathrm{LL}$ \\
Shawnee & $\mathrm{UL}$ \\
Summer & $\mathrm{UL}$ \\
Sunburst & $\mathrm{UL}$ \\
Timber & $\mathrm{LL}$ \\
\hline
\end{tabular}

${ }^{\text {a }}$ High Tide has been characterized as both a UL based on nuclear simplesequence repeat markers (Cortese et al. 2010) and LL based on plastid DNA sequences (Grabowski et al. 2014).
Seeded plots ( 1.8 by $1.8 \mathrm{~m}$ ) were established in June 2008 at three locations in New Jersey: (i) the Rutgers Plant Biology and Pathology Research and Extension Farm in Freehold, NJ, (ii) a farm located in Somerset, NJ, and (iii) the Pine Barrens Golf Club in Jackson, NJ. The Freehold location was classified as a class II United States Department of Agriculture (USDA) prime farmland with a Freehold sandy loam soil (fine-loamy, mixed, active, mesic Typic Hapludults) based on the USDA web soil survey. The farm in Somerset, NJ was classified as a class IV USDA marginal land with Klinesville channery loam soil (loamy-skeletal, mixed, active mesic Lithic Dystrudepts). The Jackson, NJ location was a class V USDA marginal land with an Evesboro sand (mesic, coated Lamellic Quartzipsamments).

Disease evaluation. Switchgrass cultivars were first visually evaluated for percent disease by using a 1-to-10 rating scale, where 1 was equal to $100 \%$ disease and 10 was equal to $0 \%$ disease. For this analysis, data were transformed to percent disease ( 0 to $100 \%)$ caused by natural epidemics of $C$. navitas on 14 June 2010.

Experimental design and statistical analyses. The experiment was arranged as a randomized complete block design with six replications at each location; three replications received nitrogen at $50 \mathrm{~kg} \mathrm{ha}^{-1}$ in the spring of each year and three replications received no nitrogen fertilization. All data were subjected to analysis of variance using the MIXED procedure in the Statistical Analysis System (SAS v. 9.1; SAS Institute Inc., Cary, NC). Analysis indicated that nitrogen was not significant in affecting disease severity and, therefore, data were pooled across the nitrogen treatment. Data were analyzed by mixed-model analysis, assuming cultivar and location to be fixed and replication (nested within location) to be random. Differences were assessed using the SLICE option in the LSMEANS statement and means were separated using Fisher's protected least significant difference test $(P \leq 0.05)$. Data were examined for violations of assumptions by inspection of plots of standardized residuals, and a single-degree-offreedom (SDOF) contrast was conducted to compare the response of LL versus UL ecotypes to anthracnose.

Experiment 2. Plant material and soil type. In July 2007, five genotypes from each of 10 different switchgrass cultivars or populations were selected from a spaced-plant screening nursery that was established at the Rutgers University Plant Biology and Pathology Research and Extension Farm in Freehold, NJ (Table 2). Individual clones from each cultivar or population were given a clone number from 1 through 5 . The five genotypes from each of the 10 cultivars or populations were randomly selected for a total of 50 individual clones. Each genotype was evenly divided into six vegetative replicates and planted in summer 2008. Plants received nitrogen at $56.1 \mathrm{~kg} \mathrm{ha}^{-1}$ after transplanting. In spring 2009, each replicate was further divided evenly into 3 more vegetative replicates for a total of 18 replicates/genotype and 900 individual plants. The plants were maintained in 10-cm pots in Pro-Mix HP (K.C. Shafer, York, PA) for 4 weeks prior to planting.

Table 2. Ecotype designation (upland [UL], lowland [LL]) of 10 switchgrass cultivars or populations grown and evaluated at Freehold (prime land), Somerset (marginal land), and Jackson (marginal land), New Jersey

\begin{tabular}{lc}
\hline Cultivar, population & Ecotype designation \\
\hline 9064202 & UL \\
Alamo & LL \\
Carthage & UL \\
Cave-in-Rock & UL \\
High Tide & UL \\
Kanlow & LL \\
NSU & UL \\
NSL & LL \\
Cimarron & LL \\
Timber & LL \\
\hline
\end{tabular}

${ }^{a}$ High Tide has been characterized as both a UL based on nuclear simplesequence repeat markers (Cortese et al. 2010) and LL based on plastid DNA sequences (Grabowski et al. 2014). 
Six replicates of each clone were planted in June 2009 at the three locations described above in experiment 1: (i) the Rutgers Plant Biology Research and Extension Farm in Freehold, NJ (class II USDA prime land), (ii) a farm located in Somerset, NJ (class IV USDA marginal land), and (iii) the Pine Barrens Golf Club in Jackson, NJ (class V USDA marginal land). Individual plants were spaced $0.9 \mathrm{~m}$ apart and clones received nitrogen at $56.1 \mathrm{~kg} \mathrm{ha}^{-1}$ upon transplant and in June 2010 and 2011.

Percent disease. Individual clones were evaluated for percent disease (0 to $100 \%$ ) caused by natural epidemics of $C$. navitas (as described above in experiment 1) on 26 July 2010 and 28 July 2011 at all three locations.

Experimental design and statistical analysis. The experiment was arranged as a randomized complete block design with six replications at each location for a total of 300 plants per location. All data were subjected to analysis of variance using the MIXED procedure in SAS. Data were analyzed by mixed-model analysis, assuming all effects to be fixed except replication, which was nested within location. Year was considered to be a repeated measure and differences were assessed using the SLICE option in the LSMEANS statement and means were separated using Fisher's protected least significant difference test $(P \leq 0.05)$. Data were examined for violations of assumptions by inspection of plots of standardized residuals. An SDOF contrast was conducted to compare the response of LL versus UL ecotypes to anthracnose. Kendall's $\tau$ and Spearman's rank correlation coefficients were determined using the CORR procedure in SAS.

Clonal repeatability estimates, which provide estimates of an upper limit for broad-sense heritability (Falconer and Mackay 1996), for anthracnose tolerance were determined from restricted maximumlikelihood variance and covariance components using the MIXED procedure in SAS. All effects were treated as random for the purpose of obtaining variance components as a means to estimate repeatability of clonal mean performance. Clonal repeatability was calculated on a clonal mean $(R \mathrm{c})$ basis as well as on a single-plant basis $(R \mathrm{sp})$ using the formulas $R \mathrm{c}=\sigma^{2}{ }_{\mathrm{d}} /\left\{\left[\left(\sigma^{2}{ }_{\mathrm{c}}+\sigma_{\mathrm{cy}}^{2}\right) / y\right]+\left[\sigma_{\mathrm{cl}}^{2} / l\right]+\left[\sigma_{\mathrm{cr}(\mathrm{l})}^{2} / r l\right]+\left[\sigma^{2}{ }_{\mathrm{cly}} / l y\right]+\left[\sigma_{\mathrm{e}}^{2} /\right.\right.$ $r l y]\}$ and $R \mathrm{sp}=\sigma_{\mathrm{c}}^{2}\left(\sigma^{2}{ }_{\mathrm{c}}+\sigma_{\mathrm{cy}}^{2}+\sigma_{\mathrm{cl}}^{2}+\sigma_{\text {cr(l) }}^{2}+\sigma_{\text {cly }}^{2}+\sigma_{\mathrm{e}}^{2}\right)$, where $\sigma^{2}{ }_{c}=$ the total genetic variance of clones, $\sigma_{c y}^{2}=$ clone-year variance, $\sigma^{2}{ }_{\mathrm{cl}}=$ clone-location variance, $\sigma_{\mathrm{cr}(\mathrm{l})}^{2}=$ clone-replication within location variance, $\sigma_{\text {cly }}^{2}=$ clone-year-location variance, and $\sigma_{\mathrm{e}}^{2}=$ experimental error (clone-year-replication within location). Letters in the denominator refer to years $(y$, two), locations $(l$, three), and the number of replications (six) within locations $(r, 18)$ (Poehlman and Sleper 2006).

Stability analyses were conducted to determine the response of each clone to anthracnose. The method utilized is similar to analyses conducted by Casler et al. (2001), Bonos et al. (2004), and Bokmeyer et al. (2009). For this analysis, each location in each year was considered a separate environment. For each environment, clonal means were computed and converted into a deviation from the location mean using the formula $x i j=X i j-M j$, where $X i j=$ the observation of the $i$ th population at the $j$ th location and $M j=$ mean of the $j$ th location (Casler et al. 2001). The least significant value (LSV) for $\alpha=$ 0.05 was computed using the formula $\left.t_{\alpha / 2}, d f e \sqrt{[} \operatorname{MSe}(1 / r+1 / r n)\right]$, where MSe was determined from the error term of the analysis of variance from each location, $r=$ number of replications, and $n=$ total number of clones in the analysis. Negative deviations from the year-location mean indicated that a clone exhibited a lower than average value for that environment. Positive deviations from the

Table 3. Analysis of variance summary for 14 switchgrass cultivars evaluated at Freehold (prime land), Somerset (marginal land), and Jackson (marginal land) in New Jersey in $2010^{\mathrm{a}}$

\begin{tabular}{lcccc}
\hline $\begin{array}{l}\text { Source of } \\
\text { variation }\end{array}$ & $\begin{array}{c}\text { Numerator } \\
\text { DF }\end{array}$ & $\begin{array}{c}\text { Denominator } \\
\text { DF }\end{array}$ & $\boldsymbol{F}$ value & $\boldsymbol{P}$ value \\
\hline Cultivar & 13 & 75 & 7.1 & $<0.0001$ \\
Location & 2 & 6 & 24.25 & 0.001 \\
Cultivar $\times$ location & 26 & 75 & 1.71 & 0.03 \\
Lowland vs. upland & $\ldots$ & $\ldots$ & 1.57 & 0.21 \\
\hline
\end{tabular}

a Anthracnose severity ranged from 0 to $100 \%$ from a natural epidemic caused by Colletotrichum navitas. year-location mean indicated that a clone exhibited a higher than average value for that environment. A clone was considered stable across environments if it had a deviation from the year-location mean significantly less than (stable-low) or greater than (stablehigh) the LSV for all year-locations.

\section{Results}

Experiment 1. Genotype-environment interactions. The main effects of cultivar and location were important in affecting anthracnose severity (Table 3 ). Among the bottom-ranking clones across all three locations were the UL ecotypes Sunburst, Pathfinder, and KY 1625, which all had $60 \%$ or greater disease (data not shown, $P \leq 0.05$ ). Among the three locations, average disease ratings were highest at Jackson (56.2\%), intermediate at Freehold (47.5\%), and lowest at Somerset (37.9\%) (data not shown, $P \leq 0.05$ ).

The interaction between clone and location significantly affected anthracnose severity (Table 3 ). The greatest range in percent disease was detected at the Freehold location (76.7 to $31.7 \%$ disease) compared with the Somerset (50.0 to $23.3 \%$ ) and Jackson (73.3 to $38.3 \%$ ) locations (Table 4). At the Freehold location, several cultivars, including the LL ecotypes Timber (31.7\% disease) and Performer (31.7\% disease) and the UL ecotype High Tide $33.3 \%$ disease), had the lowest amount of disease in comparison with six of the other cultivars evaluated. Disease severity at Freehold was highest for the UL ecotypes Sunburst, Pathfinder, and KY 1625 (76.7, 76.7, and 73.3\% disease, respectively). At the Somerset location, the LL ecotypes Timber and Kanlow had the same amount of disease (26.7\%), which was significantly lower than Alamo (50.0\% disease). All other cultivars evaluated at Somerset had similar amounts of anthracnose. LL BoMaster had the lowest amount of disease $(38.3 \%)$ at Jackson compared with KY 1625, Pathfinder, Summer, Blackwell, Shawnee, and Cave-in-Rock, which are all UL ecotypes.

The difference in response between LL and UL ecotypes was not significant when data were analyzed for all cultivars at all locations (Table 3); however, the SDOF contrast comparing LL and UL performance at each location indicated that LL ecotypes had significantly lower disease at Somerset and Jackson compared with the UL ecotypes evaluated. At the Freehold location, there was no significant difference between UL and LL ecotypes (Table 4).

Experiment 2. Genotype-environment interactions. The main effects of clone and year along with all two- and three-way combinations of clone, year, and location were significant in affecting

Table 4. Mean percent anthracnose from 2010 for 14 switchgrass cultivars grown at Freehold (prime land), Somerset (marginal land), and Jackson (marginal land), New Jersey ${ }^{a}$

$\%$ Anthracnose per location

\begin{tabular}{lcccc} 
Cultivar & Ecotype $^{\mathbf{b}}$ & Freehold & Somerset & Jackson \\
\hline Alamo & LL & 50.0 & 50.0 & 53.3 \\
Blackwell & UL & 41.7 & 41.7 & 61.7 \\
BoMaster & LL & 41.7 & 45.0 & 38.3 \\
Carthage & UL & 36.7 & 31.7 & 51.7 \\
Cave-in-Rock & UL & 40.0 & 43.0 & 60.0 \\
High Tide & UL & 33.3 & 35.0 & 56.7 \\
Kanlow & LL & 46.7 & 26.7 & 51.7 \\
KY 1625 & UL & 73.3 & 45.0 & 73.3 \\
Pathfinder & UL & 76.7 & 45.0 & 68.3 \\
Performer & LL & 31.7 & 35.0 & 45.0 \\
Shawnee & UL & 40.0 & 35.0 & 60.0 \\
Summer & UL & 45.0 & 41.0 & 63.3 \\
Sunburst & UL & 76.7 & 46.7 & 58.3 \\
Timber & LL & 31.7 & 26.7 & 45.0 \\
LSD & $\ldots$ & 10.0 & 22.5 & 20.0 \\
LL vs. UL & $\ldots$ & NS & $* *$ & $* *$ \\
\hline
\end{tabular}

a Anthracnose severity ranged from 0 to $100 \%$ from a natural epidemic caused by Colletotrichum navitas. NS and ** indicate nonsignificant or significant at $P \leq 0.05$, respectively.

${ }^{\mathrm{b}} \mathrm{LL}=$ lowland and UL = upland ecotypes.

${ }^{c}$ Least significant difference. 
anthracnose severity (Table 5). A significant year-location effect was observed, where the Freehold location showed the lowest mean percent anthracnose in $2010(37.8 \%)$ but the greatest in 2011 (32.7\%), and the Jackson location showed the highest mean percent anthracnose in 2010 (44.0\%) but the lowest in 2011 (24.4\%) (data not shown, $P \leq 0.05$ ). The SDOF contrast comparing LL versus UL ecotypes was significant, with LL ecotypes having significantly less disease than UL ecotypes.
Anthracnose rankings varied among the clones by location and year; the five clones with the least and most anthracnose are presented in 2010 (Table 6) and 2011 (Table 7). At the Freehold location, the five best clones in 2010 consisted of four UL ecotypes, including High Tide 4, High Tide 5, High Tide 3, and 'Carthage' 5 (16.7, 16.7, 20.0, and $25.0 \%$ disease, respectively) and one LL clone (Timber 4; $20.0 \%$ disease). The bottom-ranking clones with the highest percent disease in Freehold were all UL ecotypes and included Cave-in-Rock 5 (58.3\%),

Table 5. Analysis of variance summary for 50 clones evaluated at Freehold (prime land), Somerset (marginal land), and Jackson (marginal land), New Jersey, in 2010 and $2011^{\mathrm{a}}$

\begin{tabular}{|c|c|c|c|c|}
\hline Source of variation & Numerator DF & Denominator DF & $F$ value & $P$ value \\
\hline Clone & 49 & 1,430 & 33.29 & $<0.0001$ \\
\hline Year & 1 & 30 & 250.05 & $<0.0001$ \\
\hline Location & 2 & 30 & 0.76 & 0.48 \\
\hline Clone $\times$ year & 49 & 1,430 & 4.52 & $<0.0001$ \\
\hline Clone $\times$ location & 98 & 1,430 & 4.85 & $<0.0001$ \\
\hline Year $\times$ location & 2 & 30 & 25.92 & $<0.0001$ \\
\hline Clone $\times$ location $\times$ year & 98 & 1,430 & 1.91 & $<0.0001$ \\
\hline Lowland vs. upland & $\ldots$ & $\ldots$ & 20.35 & $<0.0001$ \\
\hline
\end{tabular}

a Anthracnose severity ranged from 0 to $100 \%$ from a natural epidemic caused by Colletotrichum navitas.

Table 6. Mean percent anthracnose for the top and bottom 5 ranked switchgrass clones out of $50^{\mathrm{a}}$

\begin{tabular}{|c|c|c|c|c|c|c|c|c|c|}
\hline \multirow[b]{3}{*}{ Rank } & \multicolumn{9}{|c|}{ Location in New Jersey } \\
\hline & \multicolumn{3}{|c|}{ Freehold } & \multicolumn{3}{|c|}{ Somerset } & \multicolumn{3}{|c|}{ Jackson } \\
\hline & Clone & Ecotype & $\%$ Anthracnose & Clone & Ecotype & $\%$ Anthracnose & Clone & Ecotype & $\%$ Anthracnose \\
\hline \multirow[t]{5}{*}{ Top 5} & HIT 4 & UL & 16.7 & HIT 4 & UL & 23.3 & TIM 4 & LL & 30.0 \\
\hline & HIT 5 & UL & 16.7 & TIM 4 & LL & 26.7 & CAR 5 & UL & 30.0 \\
\hline & HIT 3 & UL & 20.0 & CAR 3 & $\mathrm{UL}$ & 28.3 & TIM 1 & LL & 31.7 \\
\hline & TIM 4 & LL & 20.0 & CIR 4 & $\mathrm{UL}$ & 30.0 & ALM 4 & LL & 35.0 \\
\hline & CAR 5 & UL & 25.0 & HIT 1 & UL & 30.0 & CIM 3 & LL & 35.0 \\
\hline \multirow[t]{5}{*}{ Bottom 5} & CIR 5 & UL & 58.3 & NSU 1 & UL & 56.7 & 9064 & UL & 55.0 \\
\hline & NSU 5 & UL & 63.3 & NSU 2 & UL & 58.3 & NSU 2 & UL & 55.0 \\
\hline & NSU 1 & UL & 71.7 & CIM 5 & LL & 60.0 & HIT 2 & UL & 56.7 \\
\hline & NSU 2 & UL & 73.3 & NSU 5 & UL & 60.0 & NSU 4 & UL & 60.0 \\
\hline & 9065 & UL & 75.0 & 9065 & UL & 61.7 & 9061 & UL & 60.8 \\
\hline $\mathrm{LSD}^{\mathrm{b}}$ & $\ldots$ & $\ldots$ & 10.0 & $\ldots$ & $\ldots$ & 10.0 & $\ldots$ & $\ldots$ & 11.0 \\
\hline LL vs. UL & $\ldots$ & $* * *$ & $\ldots$ & $\ldots$ & NS & $\ldots$ & $\ldots$ & $* * *$ & $\ldots$ \\
\hline
\end{tabular}

Table 7. Mean percent anthracnose for the top and bottom five ranked switchgrass clones out of $50^{\mathrm{a}}$

\begin{tabular}{|c|c|c|c|c|c|c|c|c|c|}
\hline \multirow[b]{3}{*}{ Rank } & \multicolumn{9}{|c|}{ Location in New Jersey } \\
\hline & \multicolumn{3}{|c|}{ Freehold } & \multicolumn{3}{|c|}{ Somerset } & \multicolumn{3}{|c|}{ Jackson } \\
\hline & Clone & Ecotype & $\%$ Anthracnose & Clone & Ecotype & $\%$ Anthracnose & Clone & Ecotype & $\%$ Anthracnose \\
\hline \multirow[t]{5}{*}{ Top 5} & TIM 5 & $\mathrm{LL}$ & 17.0 & CIM 2 & $\mathrm{LL}$ & 16.7 & CIM 1 & $\mathrm{LL}$ & 15.0 \\
\hline & CIM 2 & LL & 18.3 & TIM 3 & LL & 17.0 & KAN 5 & LL & 15.0 \\
\hline & CIM 5 & LL & 18.3 & TIM 4 & LL & 17.0 & NSL 3 & LL & 15.0 \\
\hline & NSL 3 & LL & 18.3 & CIM 3 & LL & 18.3 & TIM 4 & LL & 15.0 \\
\hline & TIM 2 & LL & 19.0 & ALM 5 & LL & 19.0 & CIM 3 & LL & 16.7 \\
\hline \multirow[t]{5}{*}{ Bottom 5} & CAR 4 & UL & 55.0 & NSU 1 & UL & 45.0 & NSU 1 & UL & 38.3 \\
\hline & CIR 1 & UL & 61.2 & 9065 & UL & 48.3 & 9065 & UL & 39.0 \\
\hline & NSU 5 & UL & 65.0 & NSU 2 & UL & 48.3 & NSU 5 & UL & 43.3 \\
\hline & NSU 1 & UL & 71.7 & CIR 1 & UL & 53.3 & CIR 1 & UL & 46.7 \\
\hline & NSU 2 & UL & 71.7 & NSU 5 & UL & 55.0 & NSU 2 & UL & 1.7 \\
\hline $\mathrm{LSD}^{\mathrm{b}}$ & $\ldots$ & $\ldots$ & 7.0 & $\ldots$ & $\ldots$ & 13.0 & $\ldots$ & $\ldots$ & 8.0 \\
\hline LL vs. UL & $\ldots$ & $* * *$ & $\ldots$ & $\ldots$ & $* * *$ & $\ldots$ & $\ldots$ & $* * *$ & $\ldots$ \\
\hline
\end{tabular}


'NSU' 5 (63.3\%), NSU 1 (71.1\%), and NSU 2 (73.3\%). The UL clone 90642025 was the lowest-ranking clone and had the most amount of disease (75\%) compared with 47 of the other clones evaluated at Freehold in 2010. The top five clones at Somerset in 2010 were primarily UL ecotypes, including High Tide 4, Carthage 3, Cave-in-Rock 4, and High Tide 1, along with the LL ecotype Timber 4, with percent disease ranging from 23.3 to $30.0 \%$. The clones NSU 1, NSU 2, and NSU 5 (56.7, 58.3 , and $60.0 \%$ disease, respectively) were among the bottom five clones at Somerset in 2010, along with clones 'Cimarron' 5 and 90642025 (60.0 and 61.7\% disease, respectively). At the Jackson location in 2010, the UL clone Carthage 5 (30.0\% disease) was among the top ranking clones, along with the LL clones Timber 4, Timber 1, Alamo 4, and Cimarron 3 (30.0, 31.7, 35.0, and 35.0\% disease, respectively). The five clones exhibiting the most amount of anthracnose in Somerset in 2010 were all UL ecotypes, including NSU 2 and NSU
4, with ratings ranging from 55.0 to $60.8 \%$ disease. Timber 4 consistently ranked among the top five at all locations in 2010, while Carthage 5 and High Tide 4 were in the top five ranking at two locations in 2010. The clone NSU 2 consistently ranked among the bottom five at all locations in 2010, with 90642025 , NSU 1 and NSU 5 ranking in the bottom five for at least two locations in 2010. Overall, LL ecotypes had lower amounts of disease at the Freehold and Jackson locations, with no difference detected among ecotypes at Somerset (Table 6).

Across the three locations in 2011, the top five clones were all LL ecotypes, with the bottom-ranking clones being UL ecotypes (Table 7). Clones Timber 5, Cimarron 2, Cimarron 5, 'NSL' 3, and Timber 2 had the lowest percentage of disease at Freehold, ranging from 17.0 to $19.0 \%$. Disease percentage for the bottom-ranking clones ranged from $55.0 \%$ (Carthage 4) to $71.7 \%$ (NSU1 and NSU2), with the clones Cave-in-Rock 1 and NSU 5 having values intermediate to
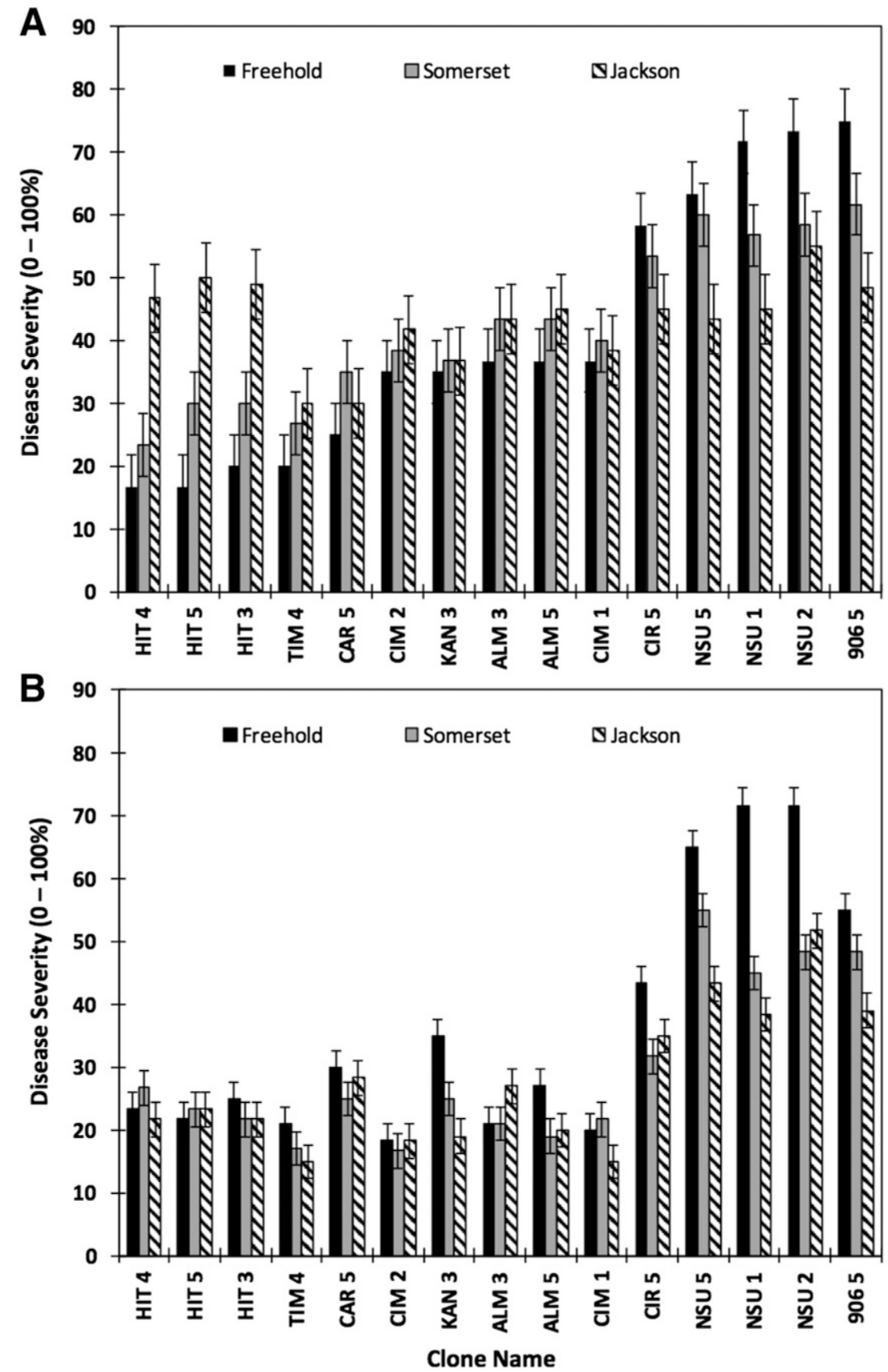

Fig. 1. Visual ratings of percent disease severity (0 to 100\%) of High Tide 4 (HIT 4), High Tide 5 (HIT 5), High Tide 3 (HIT 3), Timber 4 (TIM 4), Carthage 5 (CAR 5), Cimarron 2 (CIM 2), Kanlow 3 (KAN 3), Alamo 3 (ALM 3), Alamo 5 (ALM 5), Cimarron 1 (CIR 1), Cave-in-Rock 5 (CIR 5), NSU 5, NSU 1, NSU 2, and 9064202 (906 5) from a natural epidemic of anthracnose caused by Colletotrichum navitas and grown in Freehold (prime), Somerset (marginal), and Jackson (marginal), New Jersey, in A, 2010 and B, 2011. Vertical bars are least significant difference values $(P \leq 0.05)$ indicating statistically significant differences among the clones at each location. 
the upper and lower limits of those clones. At Somerset, Cimarron 2 (16.7\%), Timber 3 (17.7\%), Timber 4 (17.7\%), Cimarron 3 (18.3\%), and Alamo 5 (19.0\%) exhibited the lowest amount of disease compared with all other clones evaluated at the location in 2011. The bottom five ranking clones at Somerset in 2011 included NSU 1, NSU 2, and NSU 5 along with 90642025 and Cave-in-Rock 1, and disease ratings ranged from 45.0 to $55.0 \%$. The Jackson location had the lowest amount of disease in 2011 compared with the other two sites, with percentages ranging from 15.0 to $16.7 \%$. The bottom five ranking clones included NSU 1 (38.3\%), 90642025 (39.0\%), NSU 5 (43.3\%), Cave-in-Rock 1 (46.7\%), and NSU 2 (51.7\%), which had more disease compared with 47 of the other clones evaluated. The contrast of LL versus UL ecotypes indicated a significant effect, with LL ecotypes exhibiting less disease compared with UL for all three locations in 2011 (Table 7).

In order to show the variability in clonal response due to year and location, a set of 15 clones was selected based on the 2010 Freehold percent disease ratings (Fig. 1A and B). The Freehold 2010 location-year combination was used to select clones because the greatest range in ratings was detected compared with all other environments. Based on the Freehold 2010 ratings, the 15 clones included 5 exhibiting the least amount of disease (High Tide 4, High Tide 5, High Tide 3, Timber 4, and Carthage 5), 5 exhibiting moderate amounts of disease (Cimarron 2, Kanlow 3, Alamo 3, Alamo 5, and Cimarron 1), and 5 exhibiting the most disease (Cave-in-Rock 5, NSU 5, NSU 1, NSU 2, and 9064202 5). Overall, disease severity varied by clone and location for both 2010 (Fig. 1A) and 2011 (Fig. 1B). In 2010, the clones Carthage 5 and Timber 4 exhibited similar disease severity across all three locations; however, the three High Tide clones (High Tide 3, 4, and 5) had more disease at Jackson compared with the other two locations (Fig. 1A). Disease severity was similar among the middle-ranked clones across all three locations in 2010 (35.0 to $45.0 \%$ disease) but the response varied for the clones ranked in the bottom five. The amount of disease was higher for clone 90642025 in Freehold (75\%) compared with Somerset $(61.7 \%)$ and Jackson (48.3\%). In 2011, anthracnose severity was less variable among the clones at each location, with all of the top five ranked clones performing similarly at Freehold, Jackson, and Somerset (Fig. 1B). Disease severity was similar across the three locations for four of the five clones ranked in the middle in 2011, except Kanlow 3, which had higher amounts at Freehold compared with Somerset and Jackson. Disease severity was higher at Freehold for the bottom-ranking clones Cave-in-Rock 5, NSU 1, NSU 2, and NSU 5 compared with the other two locations.

Kendall's $\tau$ and Spearman's rank correlation coefficients when comparing rankings in 2010 were significant only for Freehold 2010 and Somerset 2010, with coefficient values of 0.44 and 0.56 , respectively (Table 8). In 2011, rankings between all locations were significant and generally higher (Kendall's $\tau=0.54$ to 0.65 and Spearman's rank $=0.70$ to 0.79 ). Kendall's $\tau$ and Spearman's rank correlation coefficients for comparisons between 2010 and 2011 were greatest at Freehold (0.50 and 0.65, respectively) and lowest at Somerset ( 0.23 and 0.32 , respectively).

Clonal repeatability estimates. The clonal repeatability estimate for anthracnose in switchgrass clones evaluated at three locations over 2 years was 0.78 on a clonal basis $(R \mathrm{c})$ and 0.32 on a single plant basis $(R \mathrm{sp})$ (Table 9$)$. At Freehold (prime land), $R \mathrm{c}$ was estimated to be 0.91 whereas, at the marginal locations of Somerset and Jackson, $R$ c estimates were 0.70 and 0.59 , respectively (Table 10 ). On a single-plant basis, $R$ sp was higher at Freehold (0.62) compared with Somerset (0.33) and Jackson (0.20).

Stability analysis. Stability analysis compared clonal means at individual environments to environment means and revealed only two clones that were stable for anthracnose (Table 11). The LL clone Timber 4 was positively stable and showed better tolerance to anthracnose at all location-years in this study, whereas UL clone NSU 2 was negatively stable and exhibited more damage due to anthracnose across all years and locations. All other clones were considered unstable, with variable responses across location-years. Clones 9064202 5, Cave-in-Rock 1, NSU 1, and NSU 5 were negatively stable at all environments, with the exception of 2010 Jackson, while clone Timber 1 was positively stable at all environments, except for 2010 Somerset. This was consistent with the genotype-environment interactions described above.

\section{Discussion}

Significant gains have been made in developing cultivars with improved traits such as biomass yield; however, breeding for improved disease tolerance has been limited (Casler 2012). Anthracnose has been identified as a plant pathogen that may reduce biomass yield

Table 9. Clonal repeatability estimates $(R)$ for anthracnose severity of 50 switchgrass clones grown at Freehold (prime land), Somerset (marginal land), and Jackson (marginal land), New Jersey, in 2010 and 2011

\begin{tabular}{lc}
\hline Source of variation & Variance component \\
\hline Clone & 58.2 \\
Year & 78.9 \\
Location & 0.0 \\
Replication(location) [rep $(\mathrm{loc})]$ & 0.0 \\
Clone $\times$ year & 11.7 \\
Clone $\times$ location & 18.5 \\
Clone $\times$ rep $($ loc $)$ & 7.1 \\
Year $\times$ location & 12.6 \\
Year $\times$ rep $($ loc $)$ & 4.4 \\
Clone $\times$ year $\times$ location & 13.6 \\
Error $=$ clone $\times$ year $\times$ rep $(l o c)$ & 72.3 \\
$R \mathrm{c}=0.78^{\mathrm{a}}$ & $\ldots$ \\
$R \mathrm{sp}=0.32^{\mathrm{b}}$ & $\ldots$
\end{tabular}

${ }^{\mathrm{a}} R \mathrm{c}=$ clonal repeatability estimate on a clonal basis; $95 \%$ confidence interval for $R \mathrm{c}=0.79$ to 0.76 , computed according to Knapp and Bridges (1987).

${ }^{\mathrm{b}} R \mathrm{sp}=$ clonal repeatability estimate on a single-plant basis.

Table 10. Clonal repeatability estimates of anthracnose severity for 50 switchgrass clones grown at Freehold (prime land), Somerset (marginal land), and Jackson (marginal land), New Jersey, in 2010 and 2011

\begin{tabular}{llll}
\hline & \multicolumn{3}{c}{ Location in New Jersey } \\
\cline { 2 - 4 } Anthracnose $^{\mathbf{a}}$ & \multicolumn{1}{c}{ Freehold } & \multicolumn{1}{c}{ Somerset } & Jackson \\
\hline$R \mathrm{c}$ & $0.91(0.93-0.89)$ & $0.70(0.73-0.66)$ & $0.59(0.66-0.52)$ \\
$R \mathrm{sp}$ & 0.62 & 0.33 & 0.20 \\
\hline
\end{tabular}

${ }^{a} R \mathrm{c}=$ clonal repeatability estimate on a clonal basis; $95 \%$ confidence interval for $R \mathrm{c}$ computed according to Knapp and Bridges (1987). $R \mathrm{sp}=$ clonal repeatability estimate on a single-plant basis.

Table 8. Kendall's $\tau$ (upper right) and Spearman's rank (lower left) correlation coefficients for anthracnose severity percentages of 50 switchgrass clones grown at Freehold (prime land), Somerset (marginal land), and Jackson (marginal land), New Jersey, in 2010 and 2011 a

\begin{tabular}{|c|c|c|c|c|c|c|}
\hline Location & 2010 Freehold & 2010 Somerset & 2010 Jackson & 2011 Freehold & 2011 Somerset & 2011 Jackson \\
\hline 2010 Freehold & $\ldots$ & $0.44 * * *$ & $0.16^{\mathrm{NS}}$ & $0.50 * * *$ & $0.38 * *$ & $0.34 * *$ \\
\hline 2010 Somerset & $0.56^{* * *}$ & $\ldots$ & $0.17^{\mathrm{NS}}$ & $0.21 *$ & $0.23^{*}$ & $0.17^{\mathrm{NS}}$ \\
\hline 2010 Jackson & $0.20^{\mathrm{NS}}$ & $0.19^{\mathrm{NS}}$ & $\ldots$ & $0.21 *$ & $0.39 * *$ & $0.40 * * *$ \\
\hline 2011 Freehold & $0.65^{* * *}$ & $0.30^{*}$ & $0.30^{*}$ & $\ldots$ & $0.61 * * *$ & $0.54 * * *$ \\
\hline 2011 Somerset & $0.52 * * *$ & $0.32 *$ & $0.55^{* * *}$ & $0.76^{* * *}$ & $\ldots$ & $0.65 * * *$ \\
\hline 2011 Jackson & $0.47 * *$ & $0.25^{\mathrm{NS}}$ & $0.54 * * *$ & $0.70 * * *$ & $0.79 * * *$ & $\ldots$ \\
\hline
\end{tabular}

${ }^{\mathrm{a}} \mathrm{NS}, *, * *$, and $* * *$ indicate nonsignificant or significant at $P \leq 0.05,0.01$, and 0.001 , respectively. 
and impede the production of switchgrass for biofuel in the United States (Crouch et al. 2009). In addition, research has shown that decreasing species diversity (specifically in grasslands) will result in an increase in disease pressure and severity (Mitchell et al. 2002). Consequently, the production of switchgrass in monocultures and the reduction of genetic diversity may lead to widespread epidemics of $C$. navitas. Therefore, breeding for improved tolerance to anthracnose is of high priority and research is needed to better understand the factors influencing the response of switchgrass to anthracnose.

In the current study, the greatest range in disease severity was detected at the Freehold location for both experiment 1 (Table 4) and experiment 2 (Tables 6 and 7). In addition, the highest amount of anthracnose (lowest ratings) was detected at the Jackson location in experiment 1. From an epidemiological standpoint, this makes sense, seeing as there are additional switchgrass fields at the Freehold and Jackson locations that surround the areas used for evaluation in experiment 1 and 2. Consequently, an increase in host abundance (i.e., switchgrass) could result in an increase in inoculum load and greater ranges in disease severity (Anderson and May 1979). Altogether, the differences detected both among and between locations reinforce the importance of screening and selecting improved germplasm across a wide array of environmental and climatic conditions.

A significant genotype-environment interaction was detected for both experiment 1 (Table 3 ) and experiment 2 (Table 5), along with a significant three-way interaction between cultivar, location, and year for experiment 2 (Table 5). This is consistent with other studies that have investigated the effect of environment on agronomic traits of switchgrass, including yield and forage quality (Hopkins et al. 1995a,b; McLaughlin and Kszos 2005). In experiment 1, cultivar performance varied by location but the LL ecotypes Timber and Performer generally had lower disease at all locations compared with most of the other cultivars evaluated (Table 4). Although no difference in ecotype performance was detected at Freehold, a significant contrast between LL and UL ecotypes was found for Somerset and Jackson, with the LL cultivars exhibiting less disease than UL ecotypes. This may be attributed to a competitive advantage of the LL ecotypes based on their regions of adaptation and development, which has been seen for other switchgrass traits such as yield (Casler and Boe 2003). High Tide, however, had lower disease compared with a few of the LL and most of the UL cultivars. This cultivar, although designated here as a UL ecotype, has been categorized as both a UL (based on nuclear simple-sequence repeat markers) (Cortese et al. 2010) and an LL (based on plastid DNA sequences) (Grabowski et al. 2014); therefore, it is not surprising that it exhibits lower disease than most UL. In comparison, the true UL ecotypes Sunburst, Pathfinder, and KY 1625 were among cultivars that had the highest amount of disease at all three locations. Overall, this indicates that certain UL ecotypes can be selected for improved disease tolerance but it will be important to identify germplasm that is regionally adapted to both abiotic and biotic stresses.

In contrast to experiment 1 , few clones consistently ranked in either the top or bottom five in experiment 2 (Table 6 and 7) but some trends can be seen. In 2010, there were no clones that consistently ranked in the top five at all three locations but there were four LL ecotypes (Cimarron 2, Cimarron 3, Timber 4, and NSL 2) that ranked in the top five for at least two locations. In addition, the LL ecotype Timber 4 ranked in the top five for five of the six environments evaluated in 2010 and 2011. Additionally, this clone was the only clone that was positively stable across all environments. Interestingly, there were four UL ecotypes that consistently ranked among the bottom five at all three locations in 2011, including NSU 1, NSU 2, NSU 5, and Cave-In-Rock 1. The UL ecotype 90642025 also ranked in the bottom five at two locations in 2011.

When comparing the performance of clones at all three locations over both years, certain trends emerge with regard to tolerance to anthracnose (Fig. 1A and B). Generally, UL ecotypes exhibited better performance at the marginal locations of Jackson and Somerset compared with the prime soil of Freehold (i.e., NSU clones 1, 2, and 5) in 2010 and 2011; however, these were among the clones that exhibited the most disease. The LL clones Timber 4, Alamo 3, Alamo 5, and Cimarron 2 generally had better tolerance to anthracnose, especially in 2011 across all the environments. The contrast comparing LL versus UL ecotypes confirms the trend of better performance of LL cultivars in experiment 1 and clones in experiment 2.

Table 11. Stability of anthracnose response of switchgrass clones grown at Freehold (prime land), Somerset (marginal land), and Jackson (marginal land), New Jersey, in 2010 and 2011

\begin{tabular}{|c|c|c|c|c|c|c|c|}
\hline \multirow[b]{3}{*}{ Clone } & \multirow[b]{3}{*}{ Stability $^{\mathbf{b}}$} & \multicolumn{6}{|c|}{ Deviation from location-year mean percent anthracnose ${ }^{a}$} \\
\hline & & \multicolumn{2}{|c|}{ Freehold } & \multicolumn{2}{|c|}{ Somerset } & \multicolumn{2}{|c|}{ Jackson } \\
\hline & & 2010 & 2011 & 2010 & 2011 & 2010 & 2011 \\
\hline NSU 2 & Stable high & 35.5 & 39.4 & 17.6 & 21.2 & 11.0 & 27.4 \\
\hline Timber 4 & Stable low & -17.8 & -11.3 & -14.0 & -10.1 & -14.0 & -9.3 \\
\hline 90640401 & Unstable & $10.5^{*}$ & $16.0 *$ & -2.4 & $11.2 *$ & $22.7 *$ & 4.0 \\
\hline 90642025 & Unstable & $37.2 *$ & $22.7 *$ & $21.0 *$ & $21.2 *$ & 4.3 & $14.7 *$ \\
\hline Carthage 4 & Unstable & 2.2 & $22.7 *$ & 1.0 & $7.9 *$ & -1.0 & $10.7 *$ \\
\hline Cave-in-Rock 1 & Unstable & $17.2 *$ & $29.4 *$ & $14.3 *$ & $26.2 *$ & 2.7 & $22.4 *$ \\
\hline Cave-in-Rock 5 & Unstable & $20.5 *$ & $11.0 *$ & $12.6^{*}$ & 4.6 & 1.0 & $10.7 *$ \\
\hline Cimarron 1 & Unstable & -1.1 & $-12.3 *$ & -0.7 & $-5.4 *$ & -5.7 & $-9.3 *$ \\
\hline Cimarron 2 & Unstable & -2.8 & $-14.0 *$ & -2.4 & $-10.4 *$ & -2.3 & $-6.0 *$ \\
\hline High Tide 3 & Unstable & $-17.8 *$ & $-7.3 *$ & $-10.7 *$ & $-5.4 *$ & 5.0 & -2.6 \\
\hline High Tide 4 & Unstable & $-21.1 *$ & $-9.0 *$ & $-17.4 *$ & -0.4 & 2.7 & -2.6 \\
\hline High Tide 5 & Unstable & $-21.1 *$ & $-10.6^{*}$ & $-10.7 *$ & -3.8 & 6.0 & -1.0 \\
\hline Kanlow 1 & Unstable & -6.1 & $-7.3 *$ & -7.4 & $-7.1 *$ & -7.3 & $-6.0 *$ \\
\hline NSL 3 & Unstable & -4.5 & $-14.0 *$ & -5.7 & $-7.1 *$ & -7.3 & $-9.3 *$ \\
\hline NSL 4 & Unstable & $-7.8 *$ & $-10.6^{*}$ & -2.4 & -3.8 & -5.7 & $-6.0 *$ \\
\hline NSU 1 & Unstable & $33.9 *$ & $39.4 *$ & $16.0 *$ & $17.9 *$ & 1.0 & $14.0 *$ \\
\hline NSU 5 & Unstable & $25.5 *$ & $32.7 *$ & $19.3 *$ & $27.9 *$ & -0.7 & $19.0 *$ \\
\hline Timber 1 & Unstable & $-11.1 *$ & $-9.3 *$ & -7.4 & $-8.1 *$ & $-12.3 *$ & $-7.3 *$ \\
\hline Timber 3 & Unstable & $-9.5 *$ & $-7.3 *$ & -5.7 & $-10.1 *$ & -4.0 & $-7.3^{*}$ \\
\hline Timber 5 & Unstable & $-11.1 *$ & $-15.3 *$ & -5.7 & $-8.1 *$ & -5.7 & $-7.3^{*}$ \\
\hline LSV & $\ldots$ & 7.2 & 7.2 & 7.9 & 4.9 & 9.2 & 5.6 \\
\hline
\end{tabular}

a For unstable clones, $*$ indicates that clone deviation from location-years mean percent anthracnose is significantly greater or less than the least significant value (LSV) at $P \leq 0.05$.

b Stability was assigned to a particular clone if all six deviations from location-years means were significantly greater or less than the LSV $(P \leq 0.05)$ within each environment. 
Consequently, in regions where anthracnose is high (i.e., Freehold), LL ecotypes may exhibit lower disease severity compared with UL ecotypes whereas, in regions with less disease pressure and marginal soils (i.e., Somerset and Jackson), UL ecotypes may exhibit less injury associated with anthracnose. Interestingly, lower disease severity in the UL ecotype Carthage 5 indicates that selection could improve disease tolerance in the UL ecotypes.

Overall, only $4 \%$ of the 50 clones evaluated in experiment 2 demonstrated stability across the six year-location environments, suggesting that tolerance to anthracnose is influenced by environmental factors, as was indicated by the significant clone-location-year effect. Similarly, Mehta et al. (2005) found that only one of five sorghum lines evaluated for tolerance to anthracnose was stable across all environments evaluated. Ngeve et al. (2005) found comparable inconsistencies in rankings of cassava (Manihot esculenta) genotypes grown in three different environments when evaluated for tolerance to anthracnose caused by C. gloeosporioides. In contrast, Pande et al. (1994) found that $40 \%$ of sorghum lines assessed were stable for anthracnose tolerance; however, this study was conducted at five locations over a maximum of 10 years. This indicates the importance of long-term evaluations of germplasm in order to select and develop stable disease tolerance.

Clonal repeatability estimates from experiment 2 suggest that a significant portion of the variance in anthracnose damage was due to the effect of clone $(R \mathrm{c}=0.78)$; however, the lower single-plant heritability estimate $(R \mathrm{sp}=0.32)$ demonstrates that a large amount of environmental variation was present (Table 9). Therefore, evaluation of germplasm for anthracnose tolerance should include clonal replicates over multiple locations in order to efficiently screen and select for improved cultivars. The estimates determined in this study were similar to those found for other bioenergy grass species. For example, heritability estimates for sorghum genotypes ranged from 0.79 to 0.96 when evaluated by environment but were lower (0.59) when analyzed across all environments due to significant genotype-environment interactions (Burrell et al. 2015). Similarly, tolerance of corn to $C$. graminicola seems largely under genetic control, as indicated by heritability estimates ranging from 0.84 to 0.93 (Rezende et al. 2004). In contrast, broad-sense heritability estimates for sugarcane tolerance to red rot have been estimated as low as 0 but increase when large quantities of plant material are evaluated across several locations and years (Yin et al. 1996). When evaluated by location, repeatability was higher at Freehold (0.91), where disease was more variable and a wider range of severity was observed compared with both Somerset and Jackson (0.70 and 0.59, respectively) (Table 10). Again, this may be attributed to the greater amount of inoculum present at the Freehold location versus Jackson and Somerset.

In conclusion, results from experiment 1 and experiment 2 indicate that there is significant genotype-environment variation in anthracnose severity among cultivars and clones of switchgrass, with very few stable genotypes across environments. LL ecotypes have better tolerance than UL ecotypes; however, clonal repeatability estimates indicate that it should be possible to breed switchgrass cultivars for decreased anthracnose disease severity. The most efficient screening methods will include clonal evaluation at both prime and marginal soil locations for multiple years, especially in environments with large variability in disease severity. An additional consideration is that differences in disease severity may also be attributed to variability within the anthracnose pathogen. Research has shown the existence of multiple races in other Colletotrichum spp. (Crouch and Beirn 2009), although there is not a clear understanding of whether this is true for $C$. navitas. Future research may need to consider the effect of multiple $C$. navitas races as an additional selection factor.

\section{Acknowledgments}

Funding to conduct this study was provided by the New Jersey Agricultural Experiment Station, the Rutgers Center for Turfgrass Science, Northeast Sun Grant, U.S. Native Grass Breeding Consortium to Identify Regional Optimum Biomass Productivity on Marginal Land, USDA Rural Biomass Development Program,
USDA National Institute of Food and Agriculture (NIFA) grant number 200910001-05116, and the Northeast Woody and Warm-Season Biomass Consortium USDA-NIFA grant number 2012-68005-19703

\section{Literature Cited}

Anderson, R. M., and May, R. M. 1979. Population biology of infections disease: Part I. Nature 280:361-367.

Bokmeyer, J. M., Bonos, S. A., and Meyer, W. A. 2009. Broad-sense heritability and stability analysis of brown patch resistance in tall fescue. HortScience 44 289-292.

Bonos, S. A., Casler, M. D., and Meyer, W. A. 2004. Plant responses and characteristics associated with dollar spot resistance in creeping bentgrass. Crop Sci. 44:1763-1769.

Bouton, J. 2008. Improvement of switchgrass as a bioenergy crop. Pages 295-306 in: Genetic Improvement of Bioenergy Crops. W. Vermerris, ed. SpringerVerlag, New York.

Burrell, A. M., Sharma, A., Patil, N. Y., Collins, S. D., Anderson, W. F., Rooney, W. L., and Klein, P. E. 2015. Sequencing of an anthracnose-resistant sorghum genotype and mapping of major QTL reveal strong candidate genes for anthracnose resistance. Crop Sci. 55:790-799.

Casler, M. D. 2010. Changes in mean and genetic variance during two cycles of within-family selection in switchgrass. BioEnergy Res. 3:47-54.

Casler, M. D. 2012. Switchgrass breeding, genetics, and genomics. Pages 29-53 in: Switchgrass: A valuable biomass crop for energy. A. Monti, ed. Springer, New York.

Casler, M. D., and Boe, A. R. 2003. Cultivar $\times$ environment interactions in switchgrass. Crop Sci. 43:2226-2233.

Casler, M. D., Vogel, K. P., Balasko, J. A., Berdahl, J. D., Miller, D. A., Hansen, J. L., and Fritz, J. O. 2001. Latitudinal and longitudinal adaptation of smooth bromegrass populations. Crop Sci. 41:1456-1460.

Cortese, L. M., Honig, J., Miller, C., and Bonos, S. A. 2010. Genetic diversity of twelve switchgrass populations using molecular and morphological markers. BioEnergy Res. 3:262-271.

Crouch, J. A., and Beirn, L. A. 2009. Anthracnose of cereals and grasses. Fungal Divers. 39:19-44.

Crouch, J. A., Beirn, L. A., Cortese, L. M., Bonos, S. A., and Clarke, B. B. 2009. Anthracnose disease of switchgrass caused by the novel fungal species Colletotrichum navitas. Mycol. Res. 113:1411-1421.

Falconer, D. S., and Mackay, T. F. C. 1996. Quantitative Genetics. Pearson, New York.

Gonzalez-Hernandez, J. L., Sarath, G., Stein, J. M., Owens, V., Geyde, K., and Boe, A. 2009. Multiple species approach to biomass production from native herbaceous perennial feedstocks. In Vitro Cell. Dev. Biol. Plant 45:267-281.

Grabowski, P. P., Morris, G. P., Casler, M. D., and Borevitz, J. O. 2014. Population genomic variation reveals roles of history, adaptation and ploidy in switchgrass. Mol. Ecol. 23:4059-4073.

Gravert, C. E., Tiffany, L. H., and Munkvold, G. P. 2000. Outbreak of smut caused by Tilletia maclagani on cultivated switchgrass in Iowa. Plant Dis. 84:596.

Hopkins, A. A., Vogel, K. P., Moore, K. J., Johnson, K. D., and Carlson, I. T. 1995a. Genotype effects and genotype by environment interactions for traits of elite switchgrass populations. Crop Sci. 35:125-132.

Hopkins, A. A., Vogel, K. P., Moore, K. J., Johnson, K. D., and Carlson, I. T. 1995b. Genotypic variability and genotype $\times$ environment interactions among switchgrass accessions from the Midwestern USA. Crop Sci. 35:565-571.

Knapp, S. J., and Bridges, W. C., Jr. 1987. Confidence interval estimators for heritability for several mating and experiment designs. Theor. Appl. Genet. 73:759-763.

Li, Y., Windham, M., Trigiano, R., Wadl, P., Moulton, K., Windham, A., and Spiers, J. 2009. Anthracnose: A new disease of switchgrass. (Abstr.) Phytopathology 99:S72.

McLaughlin, S. B., and Kszos, L. A. 2005. Development of switchgrass (Panicum virgatum) as a bioenergy feedstock in the United States. Biomass Bioenergy 28 515-535.

Mehta, P. J., Wiltse, C. C., Rooney, W. L., Collins, S. D., Frederiksen, R. A., Hess, D. E., Chisi, M., and TeBeest, D. O. 2005. Classification and inheritance of genetic resistance to anthracnose in sorghum. Field Crops Res. 93:1-9.

Missaoui, A. L., Paterson, A. H., and Bouton, J. H. 2006. Molecular markers for the classification of switchgrass (Panicum virgatum L.) germplasm and to assess genetic diversity in three synthetic switchgrass populations. Genet. Resour. Crop Evol. 53:1291-1302.

Mitchell, C. E., Tilman, D., and Groth, J. V. 2002. Effects of grassland species diversity, abundance, and composition on foliar fungal disease. Ecology 83: $1713-1726$

Ngeve, J. M., Dixon, A. G. O., and Nukenine, E. N. 2005. The influence of host genotype $x$ environment interactions on response of cassava anthracnose disease in diverse agro-ecologies in Nigeria. Afr. Crop Sci. J. 13:1-11.

Pande, S., Bandyopadhyay, R., Blümmel, M., Rao, J. N., Thomas, D., and Navi, S. S. 2003. Disease management factors influencing yield and quality of sorghum and groundnut crop residues. Field Crops Res. 84:89-103.

Pande, S., Thakur, R. P., Karunakar, R. I., Bandyopadhyay, R., and Reddy, B. V. S. 1994. Development of screening methods and identification of stable resistance to anthracnose in sorghum. Field Crops Res. 38:157-166. 
Parrish, D. H., and Fike, J. H. 2005. The biology and agronomy of switchgrass for biofuels. Crit. Rev. Plant Sci. 24:423-459.

Poehlman, J. M., and Sleper, D. A. 2006. Breeding Field Crops. Blackwell Publishing, Ames, IA.

Rezende, V. F., Vencovsky, R., Cárdenas, F. E. N., da Silva, H. P., Bearzoti, E., and Camargo, L. E. A. 2004. Mixed inheritance model for resistance to anthracnose leaf blight in maize. Crop Breed. Appl. Biotechnol. 4:115-122.

Sanderson, M.A. 2008. Upland switchgrass yield, nutritive value, and soil carbon changes under grazing and clipping. Agron. J. 100:510-516.

Shen, Z. X., Parrish, D. J., Wolf, D. D., and Welbaum, G. E. 2001. Stratification in switchgrass seeds is reversed and hastened by drying. Crop Sci. 41:1546-1551.

Singh, N. 2008. Sustainable management of redrot disease of sugarcane. Indian Sugar 58:21-30.

Thomas, M. D. 1995. Sorghum anthracnose research in West Africa: A look at the present and the future. Pages 127-136 in: Disease Analysis through
Genetics and Biotechnology-Interdisciplinary Bridges to Improve Sorghum and Millet Crops. J. F. Leslie and R. A. Frederiksen, eds. IOWA University Press, Ames.

United States Congress. 2007. Energy Independence and Security Act. One Hundred Tenth Congress of the United States of America. Pub. L No. 110-140.

Vance, C. P., Kirk, T. K., and Sherwood, R. T. 1980. Lignification as a mechanism of disease resistance. Annu. Rev. Phytopathol. 18:259-288.

Varvel, G. E., Vogel, K. P., Mitchell, R. B., Follett, R. F., and Kimble, J. M. 2008 Comparison of corn and switchgrass on marginal soils for bioenergy. Biomass Bioenergy 32:18-21.

Waxman, K. D., and Bergstrom, G. C. 2011. First report of anthracnose caused by Colletotrichum navitas on switchgrass in New York. Plant Dis. 95: 1032.

Yin, H., Hoy, W., and Milligan, S. B. 1996. Evaluation and heritability of resistance to sugarcane red rot. Phytopathology 86:662-667. 